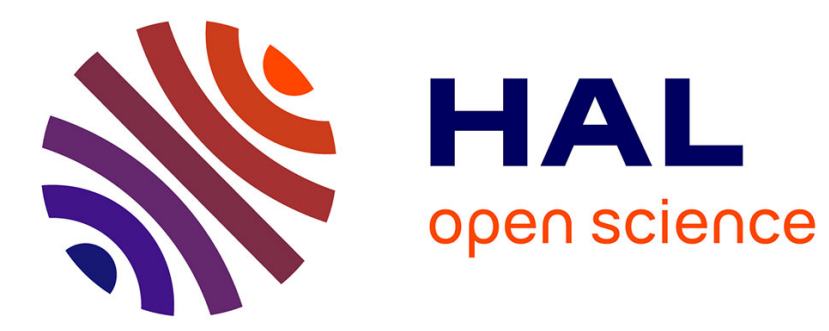

\title{
Investigations of Epitaxial Ga: YIG(111) Films by Brillouin Light Scattering and Microwave Spectroscopy
}

J. Boyle, J. Booth, A. Boardman, I. Zavislyak, V. Bobkov, V. Romanyuk

\section{To cite this version:}

J. Boyle, J. Booth, A. Boardman, I. Zavislyak, V. Bobkov, et al.. Investigations of Epitaxial Ga: YIG(111) Films by Brillouin Light Scattering and Microwave Spectroscopy. Journal de Physique IV Proceedings, 1997, 07 (C1), pp.C1-497-C1-498. 10.1051/jp4:19971203 . jpa-00254854

\section{HAL Id: jpa-00254854 https://hal.science/jpa-00254854}

Submitted on 1 Jan 1997

HAL is a multi-disciplinary open access archive for the deposit and dissemination of scientific research documents, whether they are published or not. The documents may come from teaching and research institutions in France or abroad, or from public or private research centers.
L'archive ouverte pluridisciplinaire HAL, est destinée au dépôt et à la diffusion de documents scientifiques de niveau recherche, publiés ou non, émanant des établissements d'enseignement et de recherche français ou étrangers, des laboratoires publics ou privés. 


\title{
Investigations of Epitaxial Ga:YIG(111) Films by Brillouin Light Scattering and Microwave Spectroscopy
}

\author{
J.W. Boyle, J.G. Booth, A.D. Boardman, I. Zavislyak*, V. Bobkov* and V. Romanyuk* \\ Physics Department, University of Salford, Salford M5 4WT, U.K. \\ * Radiophysics Department, Taras Shevchenko University, Kiev, 252017, Ukraine
}

\begin{abstract}
Brillouin light scattering and microwave spectroscopy measurements have enabled the room temperature magnetic characteristics of five $\mathrm{Y}_{3} \mathrm{Fe}_{5-x} \mathrm{Ga}_{x} \mathrm{O}_{12}(111)$ films with $0 \leq x \leq 0.73$ to be obtained. The film thicknesses ranged from 7 to 10 microns. The BLS measurements gave stiffness factors ranging from 5.52 to $8.77 .10^{-9}$ Oe.cm ${ }^{2}$. This variation is attributed to the occupation by Ga atoms of the $A$ and $D$ sites causing a decrease in $J_{\text {ad. }}$. The values of $4 \pi \mathrm{M}_{s}$ and $\gamma$ deduced were in good agreement with those obtained by microwave spectroscopy which examined the frequencies of the MSBVW and MSFVW excitations generated by a periodic array of microstrips. $4 \pi \mathrm{M}_{s}$ decreased from $1.740 \mathrm{kG}$ for $x=0$ to $0.645 \mathrm{kG}$ for $\mathrm{x}=0.73$. A cubic anisotropy field $H_{K}$ of $\sim 45$ Oe and first and second order uniaxial anisotropy fields $\mathrm{H}_{\mathrm{u} 1}$ and $\mathrm{H}_{\mathrm{u} 2}$ of $\sim-70$ and $50 \mathrm{Oe}$ respectively were obtained.
\end{abstract}

\section{INTRODUCTION}

The properties of epitaxial ferrite films are known to be different from those of bulk material as a result of distortions of the basic crystal symmetry. The anisotropy energy may be represented in terms of a combined uniaxial and cubic symmetry. Brillouin light scattering and microwave spectroscopy measurements described here have enabled the room temperature magnetic characteristics of a series of five $\mathrm{Y}_{3} \mathrm{Fe}_{5-\mathrm{x}} \mathrm{Ga}_{\mathrm{x}} \mathrm{O}_{12}$ single crystal (111) films to be determined.

\section{EXPERIMENTAL TECHNIQUES}

The single crystal garnet films were prepared by liquid phase epitaxy. The substrate material was (111) oriented gadolinium gallium garnet and the film thicknesses were in the range 7-10 microns. Brillouin light scattering was carried out using a backscattering technique with the incident light $(\lambda=514.9 \mathrm{~nm})$ perpendicular to the static applied field $\mathrm{H}$ with $0 \leq \mathrm{H} \leq 5.0 \mathrm{kOe}$. A multipass $(3+3)$ Fabry-Perot interferometer was used to detect the frequency shifts as a function of applied field and the magnon frequencies $\omega_{K}$ were fitted to the equation,

$$
\omega_{\kappa}=\gamma\left[\left(H+D_{e x} \kappa^{2}\right)\left(H+D_{e x} \kappa^{2}+4 \pi M_{s}\right)\right]^{0.5}
$$

where $\gamma$ is the gyromagnetic ratio, $D_{\mathrm{ex}}$ the stiffness factor and $4 \pi \mathrm{M}_{s}$ the saturation induction. The magnon wavenumber for back scattering is $\kappa=2(2 \pi / \lambda) n$ where $n$ is the refractive index for the light. For this system $n$ is strongly dependent on Ga content [1]. By fitting the results to equation (1) the parameters $D_{\text {ex }} \gamma$ and $4 \pi M_{s}$ were determined. Figure 1 shows the variation of the spin wave stiffness constants so deduced for all the samples. Microwave spectroscopy was carried out at X-band and employed both backward and forward MSW generated under appropriate field orientations by a stripline array in contact with the film. The microstrip structure excites MSFVW or MSBVW propagating in a direction perpendicular to the strips with wavenumbers $\kappa_{\mathrm{m}}=2 \pi \mathrm{m} / \tau$ where $\tau$ is the stripline periodicity and $\mathrm{m}$ is integral. 


\section{RESULTS AND DISCUSSION}

3.1 Brillouin light scattering. The exchange energy $\mathrm{E}$ of the acoustic spin wave mode for pure $\mathrm{YIG}$ at $0 \mathrm{~K}$ has been given by Keffer [2] as,

$$
\mathrm{E}=(5 / 16) \kappa^{2} \mathrm{a}^{2}\left\{8 \mathrm{~J}_{\mathrm{aa}}+3 \mathrm{~J}_{\mathrm{dd}}-5 \mathrm{~J}_{\mathrm{ad}}\right\}
$$

where the J's are the appropriate exchange integrals for interactions between the sites indicated and a is the lattice parameter. The spin wave stiffness parameter is the coefficient of $\kappa^{2}$ in this expression. Previous studies [3] on polycrystalline bulk material have shown that occupation of both $\mathrm{A}$ and $\mathrm{D}$ sites occurs for Ga substitution and Dionne [4] has given the variation of the molecular field coefficients as a function of $x$. Using these values together with equation (2) one finds that the ratio of the stiffnesses at $x=0.73$ and $x=0$ is $D_{0.73} D_{0}=1.40$ compared with our experimentally observed ratio (see Table 1 ) of 1.59 . In fact it is known that in single crystal films because of the growth conditions the site occupation is somewhat different from bulk[5]

Table 1. Thickness s, magnetic induction $4 \pi \mathrm{M}_{s}$, cubic anisotropy field $\mathrm{H}_{\mathrm{K}}$, first and second order uniaxial anisotropy fields $H_{\mathrm{u} 1}$ and $\mathrm{H}_{\mathrm{u} 2}$ and spin wave stiffness coefficient $D_{\mathrm{ex}}$ as a function of $G$ a content $\mathrm{x}$.

$\begin{array}{ccccccc}\mathrm{x} & \mathrm{s} & 4 \pi \mathrm{M}_{\mathrm{s}} & \mathrm{H}_{\mathrm{K}} & \mathrm{H}_{\mathrm{u} 1} & \mathrm{H}_{\mathrm{u} 2} & \mathrm{D}_{\mathrm{ex}} \\ & \mu \mathrm{m} & \mathrm{kG} & \mathrm{Oe} & \mathrm{Oe} & \mathrm{Oe} & 10^{-9} \mathrm{Oe.cm}^{2} \\ 0 & 7.10 & 1.740 & -46 & -73 & 32 & 5.52 \\ 0.34 & 9.60 & 1.180 & -45 & -98 & 48 & 7.00 \\ 0.42 & 9.40 & 1.025 & -44 & -85 & 59 & 7.10 \\ 0.60 & 9.45 & 0.760 & -45 & -86 & 62 & 8.27 \\ 0.73 & 10.20 & 0.645 & -50 & -19 & 73 & 8.77\end{array}$

3.2 Microwave spectroscopy. The anisotropy energy $U$ was assumed to contain both cubic and uniaxial terms,

$$
\mathrm{U}=\mathrm{K}\left(\alpha_{1}^{2} \alpha_{2}^{2+}+\alpha_{2}^{2} \alpha_{3}^{2}+\alpha_{1}^{2} \alpha_{3}^{2}\right)-\mathrm{K}_{\mathrm{u} 1} \alpha_{\perp}^{2}-\mathrm{K}_{\mathrm{u} 2} \alpha_{\perp}^{4}
$$

where $\mathrm{K}_{\mathrm{u} 1}$ and $\mathrm{K}_{\mathrm{u} 2}$ are the first and second order uniaxial anisotropy constants and $\mathrm{K}$ is the cubic anistropy constant. The direction cosines of the magnetization in a cubic coordinate system are $\alpha_{1} \alpha_{2}$ and $\alpha_{3}$, and $\alpha_{\perp}$ is the cosine of the angle of the magnetization to the plane normal. The dependence of the MSW frequencies with the above form of anisotropy on $k$ have been determined analytically by Danilov et al[6] and a least squares fit (see Figure 2) when coupled with the observation of the field required for saturation gives all three magnetic anisotropy fields listed in Table 1. Further work on annealed films is in progress. The work is supported under Nato Grant \# 941194.

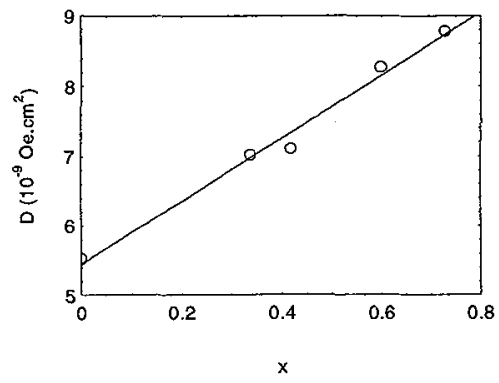

Fig 1. Variation of $D_{e x}$ with Ga content $x$.

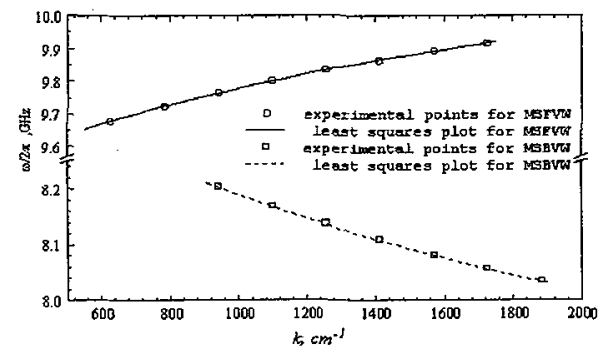

Fig 2. MSBVW and MSFVW frequencies versus $\kappa$,

\section{REFERENCES}

[1]Oderich,V.A., Riban,V.A., Gul'chuk,P.F.:Sov.Phys.Solid State 20 (1978) 2010.

[2]Keffer,K.:Handbuch der Physik XVIII/2 (H.P.J.Wijn,ed., Springer-Verlag, 1966) 1.

[3]Geller,S., Williams,H.J., Esoinosa,G.P., Sherwood,R.C.:Bell System Tech.J.43 (1964) 565.

[4]Dionne, G.F.: J. Appl. Phys. 41 (1970) 4784.

[5]Hansen,P., Roschmann,P., Tolksdorf,W.: J Appl.Phys. 45 (1974) 2728.

[6]Danilov,V.V., Zavislyak,I.V., Balinsky,M.G.:Spinwave Electrodynamics, Kiev, Lybid' (in Russian). 